\title{
GAMBARAN PERKEMBANGAN PSIKOSOSIAL MAHASISWA KEPERAWATAN DI SURABAYA
}

\section{A DESCRIPTION OF THE PSYCHOSOCIAL DEVELOPMENT OF NURSING STUDENTS IN SURABAYA}

\author{
Sukma Ayu Candra Kirana ${ }^{1 *}$, Diyan Mutyah ${ }^{2}$, Nisha Dharmayanti Rinarto ${ }^{3}$ \\ ${ }^{* 1}$ Stikes Hang Tuah Surabaya, Jl Gadung No. 1 Rumkital dr Ramelan Surabaya Jawa Timur, email: \\ sukmakirana89@gmail.com, Indonesia \\ ${ }^{2}$ Stikes Hang Tuah Surabaya, Jl Gadung No. 1 Rumkital dr Ramelan Surabaya Jawa Timur, email: \\ diyanmutyah@gmail.com, Indonesia \\ ${ }^{3}$ Stikes Hang Tuah Surabaya, Jl Gadung No. 1 Rumkital dr Ramelan Surabaya Jawa Timur, email: \\ nishadr.shtsby@gmail.com, Indonesia
}

\begin{abstract}
Background: Young adulthood is a stage of human psychosocial development where individuals begin to accept and assume heavier responsibilities. At this stage of age, intimate relationships begin to be explored and experienced development, this is in line with the reproductive period that starts perfect. Intimacy is how individuals are able to foster intimate / close relationships and love with others.

Objective: The purpose of this study is to get a description of the psychosocial development of nursing students in the Surabaya area using an intimacy questionnaire.

Methods: The research method used was descriptive analysis by taking a sample of 50 nursing students from 5 nursing institutions in Surabaya so that the total sample was 250.

Results: The results in this study that discuss the psychososisal development in young adults obtained the results of most of the psychososisal development is less than optimal with 83 respondents $(33.2 \%)$ because of the age factor that produces greater than 19 years.

Conclusion: So the need for activities that can support psychosocial development in students, especially in supporting the development of intimacy so that the development of intimacy in students can be optimal. Activities that can be carried out such as sharing activities between students and lecturers so that lecturers can help students in fulfilling their development tasks, and students need to play an active role in training themselves to improve the development of intimacy in themselves.
\end{abstract}

Keywords: Development, Nursing, Student, psychosocial

\section{PENDAHULUAN}

Usia produktif adalah usia dimana seseorang penduduk memiliki usia 15-64 tahun. Indonesia memiliki generasi muda sebanyak $60 \%$ dari total penduduk Indonesia yang mencapai 250 juta jiwa, hal ini berarti bahwa populasi produktif di Indonesia dapat mencapai 195 juta jiwa pada 2040 nanti. Peningkatan usia produktif tersebut dapat meningkatkan perekonomian nasional. ${ }^{1}$ Ahli lain Hurlock (1980) membagi dewasa menjadi dewasa muda (18-40 tahun), dewasa madya (40-60 tahun), dan masa dewasa lanjut (60 tahun sampai dengan kematian). ${ }^{2}$

Usia dewasa merupakan tahapan yang diawali masa transisi dari remaja hingga dewasa yang melibatkan pengalaman dan eksplorasi yang disebut dengan emerging adulthood. ${ }^{3}$ Menurut Teori Erikson, Usia dewasa muda adalah tahap perkembangan psikososial manusia dimana individu mulai menerima dan memikul tanggung jawab yang lebih berat. Tahap usia dewasa ini hubungan 
intim mulai didalami dan mengalami perkembangan, hal ini sejalan dengan masa reproduktif yang mulai sempurna. Selain itu terdapat beberapa perubahan yang terjadi dalam penampilan, minat, sikap dan perilaku. ${ }^{4}$ Periode penyesuaian diri terhadap perubahan peran juga harus dilalui pada tahap ini yaitu berperan sebagai mahasiswa, suami atau istri, orang tua. Hal ini juga dialami oleh mahasiswa keperawatan yang berada dalam tahap dewasa muda.

Berdasarkan hasil studi pendahuluan pada mahasiswa Stikes Hang Tuah Surabaya Program Studi S1 Keperawatan, didapatkan data bahwa 7 dari 15 mahasiswa tidak tinggal bersama dengan keluarganya. Hasil wawancara yang didapatkan adalah mahasiswa tersebut merasa tidak nyaman karena harus mempersiapkan kebutuhan dirinya secara mandiri. Selain itu mahasiswa juga mengatakan bahwa dirinya bebas dari orang tua dan bisa melakukan apa saja bahkan bebas dari pertanyaan seputar akademik mereka selama perkuliahan. Namun 8 orang mahasiswa lainnya lebih senang berada di kos dan hanya keluar untuk beli makan atau mengerjakan tugas. Lebih suka menyendiri dikamar daripada menjalin hubungan dengan teman sebayanya. 4 dari 8 mahasiswa tersebut mengaku bahwa belum pernah menjalin hubungan dengan lawan jenis karena ingin fokus berkuliah dan tidak ingin terganggu dengan masalah lain di luar studi yang mereka jalani.
Hubungan intim yang terbentuk merupakan salah satu tugas perkembangan psikososial yang harus dipenuhi pada tahap perkembangan usia dewasa muda. ${ }^{3}$ Mampu berkomitmen dalam pekerjaan, mandiri dalam kehidupan pribadi, bertanggung jawab secara ekonomi, sosial dan emosional, memiliki konsep diri yang realistis, menyukai dirinya dan mengetahui tujuan hidup, berinteraksi dengan baik dengan keluarga, mengatasi stress akibat perubahan diri, serta menjadikan kehidupan sosial bermakna dan mempunyai nilai yang dijadikan pedoman hidupnya merupakan perilaku yang seharusnya dimiliki individu dewasa muda. ${ }^{5}$ Apabila individu dewasa muda mampu membentuk persahabatan dan hubungan dekat yang sehat dengan individu yang lain, maka intimasi dapat terwujud. ${ }^{6}$ Harapan mahasiswa untuk lulus tepat waktu, mendapatkan pekerjaan sesuai dengan yang diharapkan dan menghasilkan uang agar bisa membahagiakan orang tua dapat menjadi tekanan bagi mahasiswa itu sendiri. Oleh sebab itu peneliti ingin mengetahui gambaran perkembangan psikososial mahasiswa keperawatan di wilayah Surabaya.

\section{BAHAN DAN CARA PENELITIAN}

Penelitian ini menggunakan desain penelitian deskriptif karena penelitian bertujuan untuk mendeskripsikan atau menggambarkan dari suatu fenomena tentang perkembangan psikososial mahasiswa keperawatan di Surabaya, 
sehingga tidak melakukan analisis. Teknik sampling yang digunakan dalam penelitian ini adalah kuota sampling dimana pengambilan sampel mahasiswa keperawatan sesuai dengan kriteria yang ditentukan oleh peneliti. Sampel dari penelitian ini adalah 50 mahasiswa keperawatan dari 5 intitusi keperawatan wilayah Surabaya sehingga total sampel adalah 250 .

\section{HASIL DAN PEMBAHASAN}

Dewasa muda merupakan rentang usia di mana individu memiliki lebih banyak sahabat dan lebih banyak menghabiskan waktu bersama sahabat mereka. Dewasa muda yang memiliki jumlah sahabat terbanyak yaitu pada individu yang dalam jenjang perkuliahan. $^{3}$

Erikson menjelaskan perkembangan psikosial dewasa muda berada pada tahap keintiman versus perpisahan. Individu akan mulai mencoba untuk menjalin hubungan dengan individu lain dan membentuk keakraban dan persahabatan. ${ }^{7}$ Persahabatan dan hubungan sehat yang telah terjalin antara individu satu dengan individu yang lain dapat menjadi sebuah wujud intimasi pada dewasa muda. Namun, apabila individu tidak mampu mengembangkan diri sesuai dengan tahap perkembangan psikososial, maka individu dapat memisahkan diri dengan individu lain.

Individu akan lebih memilih untuk menarik diri dari aktivitas sosial dan lebih memiliki sedikit hubungan dengan individu

lain. ${ }^{6} \quad$ Kemampuan individu dalam bersosialisasi, berkomunikasi, dan menjalin hubungan dengan individu lain dapat dipengaruhi oleh emosi sehingga individu perlu memiliki kecerdasan emosional. $^{8}$ Kecerdasan emosional dapat disebut sebagai kecerdasan interpersonal, di mana individu mengetahui cara dalam memahami diri sendiri dan individu lain, menjalin hubungan dengan individu lain, serta mampu beradaptasi dengan lingkungan. ${ }^{9}$

Tabel 1 Frekuensi data umum: Agama, Suku, Pendidikan dan Pekerjaan Orang Tua

Mahasiswa

\begin{tabular}{|c|c|c|}
\hline $\begin{array}{c}\text { Karakteristik } \\
\text { Responden }\end{array}$ & Jumlah & $\%$ \\
\hline \multicolumn{3}{|l|}{ Agama } \\
\hline Islam & 234 & 93,6 \\
\hline Protestan & 9 & 3,6 \\
\hline Katolik & 2 & 0,8 \\
\hline Hindu & 5 & 2,0 \\
\hline \multicolumn{3}{|l|}{ Suku } \\
\hline Jawa & 230 & 92,0 \\
\hline Madura & 7 & 2,8 \\
\hline Lain - lain, & 13 & 5,2 \\
\hline \multicolumn{3}{|c|}{ Pendidikan Orang Tua Ayah } \\
\hline SD & 16 & 6,4 \\
\hline SMP & 12 & 4,8 \\
\hline SMA & 146 & 58,4 \\
\hline $\mathrm{D} 3 / \mathrm{S} 1 / \mathrm{S} 2 / \mathrm{S} 3$ & 76 & 30,4 \\
\hline \multicolumn{3}{|l|}{ Pekerjaan Ibu } \\
\hline PNS & 42 & 16,8 \\
\hline TNI/POLRI & 0 & 0 \\
\hline Swasta & 29 & 11,6 \\
\hline Wiraswasta & 34 & 13,6 \\
\hline Lain - lain, yaitu & 145 & 58,0 \\
\hline \multicolumn{3}{|l|}{ Pekeriaan Ayah } \\
\hline PNS & 36 & 14,4 \\
\hline TNI/POLRI & 64 & 25,6 \\
\hline Swasta & 57 & 22,8 \\
\hline Wiraswasta & 48 & 19,2 \\
\hline Lain - lain, yaitu & 45 & 18,0 \\
\hline \multicolumn{3}{|l|}{ Pekerjaan Ibu } \\
\hline PNS & 42 & 16,8 \\
\hline TNI/POLRI & 0 & 0 \\
\hline Swasta & 29 & 11,6 \\
\hline Wiraswasta & 34 & 13,6 \\
\hline Lain - lain, yaitu & 145 & 58,0 \\
\hline \multicolumn{3}{|l|}{ Pekerjaan Ayah } \\
\hline PNS & 36 & 14,4 \\
\hline TNI/POLRI & 64 & 25,6 \\
\hline Swasta & 57 & 22,8 \\
\hline Wiraswasta & 48 & 19,2 \\
\hline Lain - lain, yaitu & 45 & 18,0 \\
\hline
\end{tabular}


Hasil penelitian ini menunjukkan data bahwa mayoritas mahasiswa dalam penelitian ini berusia 19 tahun $(57,6 \%)$ dengan Jenis kelamin terbanyak adalah perempuan (85,6\%) Agama terbanyak adalah Islam (93,6\%) dan suku terbanyak adalah suku Jawa (92\%).

Tabel 2 Frekuensi data umum: Penghasilan Orang Tua, Tempat Tinggal, Jarak Tempat Tinggal,Sarana dan Orang terdekat Mahasiswa

\begin{tabular}{|c|c|c|}
\hline Karakteristik Responden & Jumlah & $\%$ \\
\hline \multicolumn{3}{|l|}{ Penghasilan Kedua Orang tua } \\
\hline$\leq$ Rp. $3.500 .000,-$ & 84 & 33,6 \\
\hline $\begin{array}{l}\text { Rp. 3.500.000, - s.d. Rp. } \\
\text { 5.000.000,- }\end{array}$ & 105 & 42,0 \\
\hline $\begin{array}{l}\text { Rp. 5.000.001, - s.d. Rp. } \\
\text { 10.000.000,- }\end{array}$ & 54 & 21,6 \\
\hline$\geq$ Rp. 10.000.001,-- & 7 & 2,8 \\
\hline \multicolumn{3}{|l|}{ Selama Kuliah Tinggal Bersama } \\
\hline Bersama Orang Tua & 131 & 52,4 \\
\hline Indekost & 86 & 34,4 \\
\hline Lain - lain, sebutkan & 33 & 13,2 \\
\hline \multicolumn{3}{|l|}{ Jarak Tempat Tinggal } \\
\hline$<1 \mathrm{Km}$ & 76 & 30,4 \\
\hline $1 \mathrm{Km}-10 \mathrm{Km}$ & 109 & 43,6 \\
\hline$>10 \mathrm{Km}-20 \mathrm{Km}$ & 40 & 16,0 \\
\hline$>20 \mathrm{Km}$ & 25 & 10,0 \\
\hline \multicolumn{3}{|c|}{ Sarana yang digunakan untuk Kuliah } \\
\hline Jalan Kaki & 39 & 15,6 \\
\hline Sepeda & 3 & 1,2 \\
\hline Motor & 208 & 83,2 \\
\hline Mobil & 0 & 0 \\
\hline Angkutan Umum & 0 & 0 \\
\hline \multicolumn{3}{|l|}{ Orang terdekat mahasiswa } \\
\hline Orang Tua & 182 & 72,8 \\
\hline Teman / Sahabat & 59 & 23,6 \\
\hline Lainnya, Sebutkan & 9 & 3,6 \\
\hline
\end{tabular}

Data Primer, 2019

Data Khusus penelitian ini adalah perkembangan psikososial mahasiswa keperawatan di Surabaya. Pada tabel 3 mayoritas perkembangan psikososial mahasiswa keperawatan Kurang optimal sebanyak $33,2 \%$. Hal ini disebabkan bahwa perkembangan psikososial dapat dipengaruhi oleh usia dan jenis kelamin. Individu yang berusia lebih tua lebih mampu memahami diri sendiri. $^{9}$
Tabel 3 Frekuensi data khusus Psikososial Mahasiswa Keperawatan di Surabaya

\begin{tabular}{lcc}
\hline \multicolumn{1}{c}{ Psikososial } & Frek & Presentase(\%) \\
\hline Sangat Optimal & 6 & $2,4 \%$ \\
Optimal & 45 & $18,0 \%$ \\
Cukup Optimal & 75 & $30,0 \%$ \\
Kurang Optimal & 83 & $33,2 \%$ \\
Sangat Kurang & 41 & $16,4 \%$ \\
\hline \multicolumn{1}{c}{ Mean $\mathbf{~ S D ~}$} & $\mathbf{1 6 2 , 4 9 \mathbf { 1 1 , 4 9 9 }}$ \\
\hline \multicolumn{2}{c}{ Min - Max } & $\mathbf{1 2 9 - \mathbf { 2 1 4 }}$ \\
\hline
\end{tabular}

Data Primer Tahun 2019

Individu yang memiliki usia di atas 21 tahun memiliki kemampuan yang lebih baik dalam menjalin hubungan dengan individu lain. $^{2}$ Pernyataan tersebut mendukung penelitian ini karena mayoritas responden dalam penelitian ini berusia 19 tahun.

Selain itu, intimasi dapat terbentuk apabila individu telah sukses melampaui tugas sistem perkembangan pada tahap sebelumnya. $^{3} \quad$ Sistem perkembangan psikoseksual, Erikson (1969 dalam Ega, 2012) mengungkapkan bahwa jenis kelamin dapat berpengaruh pada perkembangan intimasi individu. Penelitian oleh Jones dan Dembo (1989) mendapatkan hasil bahwa perempuan mempunyai tingkat intimasi lebih tinggi daripada laki-laki. ${ }^{10}$ Penelitian oleh Ishak et al., (2011) mendapatkan bahwa kecerdasan emosional pada individu berusia lebih dari 21 tahun lebih baik daripada individu berusia di bawah 21 tahun.

Orang tua merupakan tempat pembelajaran bagi anak yang pertama kali. Sikap orang tua dalam mengasuh anak dapat dilihat dari cara orang tua merespon dan memenuhi kebutuhan anak. ${ }^{11}$ Peneliti berasumsi perkembangan psikososial mahasiswa dapat dipengaruhi oleh pola asuh 
orang tua. Pada usia dewasa muda, individu diharapkan dapat menjalin persahabatan dan hubungan dengan individu lain. Apabila orang tua terlalu membatasi anak dengan lingkungan sekitar, maka perkembangan psikologi anak akan terhambat karena anak tidak mampu menjalin hubungan dengan individu lain maupun lingkungan sekitar. Penelitian yang dilakukan oleh Yulianto, (2017) mendapatkan bahwa adanya hubungan antara pola asuh orang tua dengan perkembangan psikososial anak. ${ }^{12}$

Kegagalan perkembangan psikososial pada dewasa muda yaitu tahap keintiman dapat menimbulkan masalah baru seperti adanya masalah pekerjaan, masalah rumah tangga, dan masalah keuangan akibat pemenuhan kebutuhan hidup yang berhubungan dengan kondisi internal individu seperti faktor sosial, keluarga, lapangan pekerjaan, maupun lingkungan dan aktivitas sehari-hari dalam kampus bagi mahasiswa sehingga diperlukan adanya pembimbingan dalam mengembangkan psikosial pada individu, terutama pada dewasa muda supaya tugas perkembangan psikosial pada tahap tersebut dapat tercapai. Apabila tugas perkembangan psikosisal pada dewasa muda tidak tercapai, dapat menyebabkan individu mengalami kesulitan dalam menjalin hubungan dekat dengan individu lain dan individu akan merasa tidak percaya diri sehingga individu akan menarik diri dari sosial. $^{13}$

\section{KESIMPULAN}

Karakteristik dewasa muda sebagian besar berusia 19 tahun dan berjenis kelamin perempuan. Perkembangan psikososial pada dewasa muda berada pada tahap intimasi dengan hasil sebagian besar mahasiswa memiliki perkembangan psikososial kurang optimal. Dalam aplikasi keperawatan perlu adanya kegiatan yang dapat menunjang perkembangan psikososial pada mahasiswa, terutama dalam menunjang perkembangan intimasi sehingga perkembangan intimasi pada mahasiswa dapat optimal. Kegiatan yang dapat dilakukan seperti adanya kegiatan sharing antara mahasiswa dengan dosen sehingga dosen dapat membantu mahasiswa dalam memenuhi tugas-tugas perkembangannya. Mahasiswa perlu berperan aktif dalam melatih diri untuk meningkatkan perkembangan intimasi pada diri mereka.

Hasil penelitian ini dapat digunakan menjadi evidence based tentang perkembangan psikososial pada dewasa muda sehingga menjadi dasar perlu diadakannya terapi dalam keperawatan jiwa yang efektif untuk mencegah munculnya masalah kesehatan jiwa.Pihak peguruan tinggi ilmu keperawatan diharapkan membentuk dan memiliki ruang serta fasilitas bimbingan konseling untuk mahasiswa, seperti TBK (Tim Bimbingan dan Konseling) atau TPM (Tim Penasihat Mahasiswa) yang dapat dimanfaatkan untuk memantau perkembangan psikologi mahasiswa. 
Untuk peneliti selanjutnya perlu diadakan penelitian lebih lanjut pada dewasa muda untuk mengetahui faktor-faktor yang dapat mempengaruhi perkembangan psikososial pada dewasa muda. Perlu diadakan penelitian tentang terapi tentang pemberian fasilitas bimbingan konseling pada mahasiswa yang dapat digunakan untuk meningkatkan perkembangan psikologi tahap intimasi pada dewasa muda. Serta penelitian lebih lanjut tentang kemampuan perkembangan psikososial tahap intimasi pada individu yang memiliki usia lebih muda, seperti pada usia remaja dan hubungan karakteristik individu dengan perkembangan psikososial tahap intimasi.

\section{TERIMA KASIH}

1. Ristekdikti, I. Jend. Sudirman JI. Pintu Satu Senayan No.RT.1, RT.1/RW.3, Gelora, Tanahabang, Kota Jakarta Pusat, Daerah Khusus Ibukota Jakarta 10270, https://ristekdikti.go.id/

2. 5 Institusi Keperawatan di Wilayah Surabaya yang telah membantu proses Penelitian hingga selesai yang tidak bisa kami sebutkan satu persatu

\section{KEPUSTAKAAN}

1. Indonesia SKR. $60 \%$ Penduduk Usia Produktif, Presiden Jokowi: Ini Peluang Kita Menangkan Persaingan. Indonesia; 2017.

2. Ishak N, Melhem MT, Jdaitawi, Farid TM, Mustafa. Moderating Effect of Gender and Age on the Relationship between Emotional Intelligence with Social and
Academic Adjustment among First Year University Students. Int J Psychol Stud. 2011;3:78-9.

3. Papalia, E D, Old SW, Feldman RD. Human Development Psikologi Perkembangan. Jakarta: Kencana Prenada Media Group; 2008.

4. Pieter HZ, Janiwarti $B$, Saragih $M$. Pengantar Psikopatologi untuk Keperawatan. Edisi 1. Jakarta: Kencana; 2011.

5. Azizah FN. Pengalaman Depresi Orang Dewasa Dengan HIVIAIDS Dalam Menjalani Tugas Perkembangan Psikososial. Universitas Indonesia; 2015.

6. Santrock JW. Life-span Development: Perkembangan Masa Hidup Jilid 2. Jakarta: Erlangga; 2003.

7. Hidayat AA. Pengantar Kebutuhan Dasar Manusia. Jakarta: Salemba Medika; 2009.

8. Potter PA, Perry AG. Fundamental Keperawatan: Konsep, proses dan praktis. Asih Y, Evriyani D, Noviestari E, Panggabean $E$, Kusrini, Sumarwati $M$, editors. Jakarta: EGC; 2005.

9. Wiska N. Hubungan Usia, Jenis Kelamin, Masa Studi dan Pengalaman Praktikum di Rumah Sakit dengan Tingkat Kecerdasan Emosional Mahasiswa IImu Keperawatan. Universitas Indonesia; 2014.

10. Ega A. Pengaruh Terapi Kelompok Terapeutik; Dewasa Muda Terhadap Perkembangan Intimasi Pada Mahasiswa Akademi Keperawatan Kabupaten Subang dan Sumedang Provisi Jawa Barat. Universitas Indonesia; 2012.

11. Utami C, Murti HAS. Hubungan Antara Kelekatan dengan Orang Tua dan Keintiman dalam Berpacaran pada Dewasa Awal. Universitas Kristen Satya Wacana; 2017.

12. Yulianto, Lestari YA, Suwito ED. Hubungan Pola Asuh Orang Tua dengan Perkembangan Psikososial Anak di TK PKK XI Winong Gempol Kabupaten Pasuruan. J Nurse Heal. 2017;6(2):21-9.

13. Fortinash KM, Worret PAH. Psychiatric Mental Health Nursing. 3rd Editio. Mosby, USA; 2012. 